DOI: $10.25100 /$ pfilosofica.v0i53.11372

\title{
RAZÓN DE ESTADO Y CIENCIA DE LA SOCIEDAD. (EL CASO DE JOSÉ EUSEBIO CARO Y SU MECÁNICA SOCIAL, NUEVA GRANADA, 1836)
}
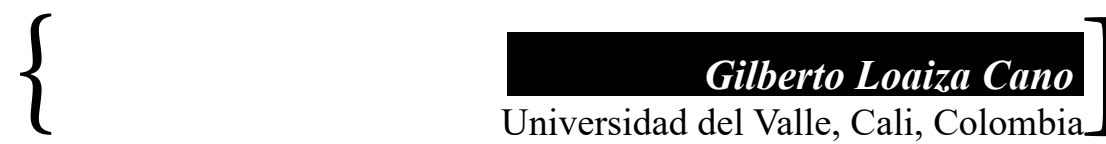

\section{Resumen}

Este ensayo es una contribución a la historia del pensamiento en Colombia y estudia el manuscrito de José Eusebio Caro (1817-1853) titulado Mecánica social (1836) en que su joven autor pretendió establecer los fundamentos de una ciencia de la sociedad cuando el Estado intentaba construir el monopolio del conocimiento jurídico. Nuestro análisis sugiere que el pensamiento colombiano de esa época estuvo afiliado a los métodos y teorías del comportamiento humano y de organización de la sociedad provenientes de algunas corrientes del pensamiento francés del siglo XVIII e inicios del siglo XIX, particularmente los postulados del grupo reunido en la Société d'Observateurs de l'homme.

Palabras clave: sociedad; comportamiento humano; historia intelectual; método analítico; razón de Estado.

Cómo citar ese artículo: Loaiza, G. (2021). Razón de Estado y ciencia de la sociedad. (El caso de José Eusebio Caro y su Mecánica Social, Nueva Granada, 1836). Praxis Filosófica, (53), 133-156. https:// doi.org/10.25100/pfilosofica.v0i53.11372

Recibido: 13 de noviembre de 2020. Aprobado: 18 de febrero de 2021. 


\title{
Reason of State and science of society. (The case of José Eusebio Caro and his Social Mechanics, Nueva Granada, 1836).
}

\author{
Gilberto Loaiza Cano ${ }^{1}$
}

\begin{abstract}
This essay is a contribution to the history of thought in Colombia and studies the manuscript of José Eusebio Caro (1817-1853) entitled Social Mechanics (1836) in which its young author intended to establish the foundations of a science of society when the State was trying to build the monopoly of legal knowledge. Our analysis suggests that Colombian thought at the time was affiliated with the methods and theories of human behavior and organization of society from some currents of French thought from the eighteenth and early nineteenth centuries, particularly those postulated from the group gathered in the Société d'Observateurs de l'Homme.
\end{abstract}

Keywords: Society; Human Behavior; Intellectual History; Analytic Method; Reason of State.

${ }^{1}$ Profesor titular del Departamento de Filosofía. Doctor en Sociología de la Universidad Paris 3-Iheal-Sorbonne Nouvelle. Autor de: Lenguaje político de la república (Medellín: Universidad Nacional, 2020); Poder letrado (Cali: Universidad del Valle, 2014); Sociabilidad, religión y política en la definición de la nación. Colombia, 1820-1886 (Bogotá: Universidad Externado). Línea de investigación: Historia intelectual de Colombia.

E-mail: gilberto.loaiza@correounivalle.edu.co ORCID: 0000-0002-6161-7149 


\title{
RAZÓN DE ESTADO Y CIENCIA DE LA SOCIEDAD. (EL CASO DE JOSÉ EUSEBIO CARO Y SU MECÁNICA SOCIAL, NUEVA GRANADA, 1836)
}

\author{
Gilberto Loaiza Cano \\ Universidad del Valle, Cali, Colombia
}

\section{Introducción}

Si hay un campo de estudios que las ciencias humanas y sociales colombianas han descuidado es el de la investigación y escritura acerca de la historia del pensamiento. Nos atrevamos a apurar, mas no a explicar en detalle, algunas conjeturas o sospechas. La primera es que se trata de un campo liminar en que cada quien considera que es tarea de la comunidad científica vecina; nos explicamos: hacer historia del pensamiento, dirán los historiadores, es asunto de filósofos; y estos, a su vez, dirán que es asunto de historiadores. Por tanto, ni los unos ni los otros han considerado que puede ser tarea compartida en que unos y otros aportan lo que saben y pueden. La otra sospecha, quizás derivada de la primera, es que nuestras ciencias humanas apenas comienzan a entender las posibilidades epistemológicas y hermenéuticas de lo que hoy se conoce como la historia intelectual; esta es una disciplina que, precisamente, ha clavado sus cimientos en la conversación con la filosofía (especialmente la filosofía política), la hermenéutica, la lingüística y la historia social y política. Sus corrientes señalan una riqueza de posibilidades que incluye -abusando de la generalización- la historia conceptual alemana cuyo nombre de cabecera es Reinhart Koselleck ${ }^{2}$, un discípulo de Hans-Georg Gadamer y Carl Schmitt; la historia conceptual de lo político que es casi sinónimo del

\footnotetext{
${ }^{2}$ Véase, por ejemplo: (Koselleck,1993); (Koselleck \& Gadamer, 1997).
} 
prolífico historiador francés Pierre Rosanvallon ${ }^{3}$; puede sumarse, a gusto de cada quien, el legado metodológico de Michel Foucault, tanto con su propuesta arqueológica como genealógica; la conversación puede ampliarse a la escuela de historiadores británicos -John G. A. Pocock ${ }^{4}$ y Quentin Skinner ${ }^{5}$, principalmente- que adoptaron con eficacia algunos postulados de la pragmática lingüística en la versión de John Searle, John Austin y Ludwig Wittgenstein; y si miramos a este lado del Atlántico, tenemos profesores muy notables en Estados Unidos, por ejemplo Martin $\mathrm{Jay}^{6}$, Russell Jacoby ${ }^{7}$ y Dominick LaCapra ${ }^{8}$. Y, más cerca de nosotros, en Argentina hay un núcleo muy consistente de investigadores reunidos en la revista Prismas.

Pues bien, amparado en esa incipiente recepción de la historia intelectual consideramos que es posible asumir una historia del pensamiento colombiano sin temor -al contrario- a cruzar linderos disciplinares y, más bien, con la necesidad de proponer y demostrar que podremos decir algo nuevo en torno a lo que hemos tenido por afirmaciones solemnes y acabadas acerca de autores, obras y momentos del pensamiento. Aún más, es muy posible que entremos en un campo inviolado de nombres, textos y discusiones que implicará una refrescante revisión de lo poco que hemos hecho y dicho en calidad de investigadores de lo que ha venido siendo la sociedad colombiana. Como dijera Pierre Rosanvallon en sus prolegómenos de una historia conceptual de lo político, puede tratarse, en nuestra realidad colombiana contemporánea, de una tardía pero activa búsqueda de principios de solución a viejos problemas, a la incertidumbre que genera el presente y que obliga a escudriñar en el pasado alguna fórmula o unas premisas que alguna vez hicieron posible, para bien o para mal, el presente de la sociedad colombiana. Como lo dijera este historiador francés, es muy posible que el objetivo implícito o explícito de estas visitas al pensamiento político del pasado sea

${ }^{3}$ Véase: (Rosanvallon, 2003). Además de sus estudios en que aplica en profundidad sus postulados de historia conceptual, por ejemplo: Rosanvallon (2011). Detrás de la obra de Rosanvallon está la huella admitida de su maestro, el filósofo Claude Lefort.

${ }^{4}$ (Pocock, 1985); del mismo autor y sobre asuntos de método en la historia del pensamiento político: (Pocock, 1989). Un paradigma de este contextualismo aplicado a la historia del pensamiento político es: (Pocock, 1975).

${ }^{5}$ De Quentin Skinner, varios viejos ensayos: (Skinner, 1969, 1, pp. 3-53; 1975, 1, pp. 209-232). Para un panorama más completo de su propuesta hermenéutica: (Skinner, 2002).

${ }^{6}$ Su opus magnum es: (Jay, 2005). Además, un ensayo de debate: (Jay, 2011, pp. 557-571).

${ }^{7}$ Aunque su trayectoria está cerca de una sociología de la vida intelectual de Estados Unidos, algunos de sus ensayos entran en la órbita de la historia intelectual, por ejemplo: (Jacoby, 1983).

${ }^{8}$ Varias de sus reflexiones están inspiradas, de modo explícito, en la obra de Martin Heidegger; al respecto: (LaCapra, 1983). También su clásico estudio sobre Jean-Paul Sartre (LaCapra, 1975). 
"rehacer la genealogía extensa de las cuestiones políticas contemporáneas para que resulten totalmente inteligibles".

\section{El manuscrito del estudiante José Eusebio Caro}

Los titubeos de una disciplina incipiente han quedado plasmados alrededor de un manuscrito de 1836 que delata una obra inconclusa y abandonada por su propio autor, el joven José Eusebio Caro (1817-1853), cuando a sus 19 años estudiaba Filosofia y Jurisprudencia en el colegio San Bartolomé, en Bogotá; para entonces, el estudiante Caro dejó un esbozo de libro titulado Mecánica social o teoría del movimiento humano, considerado en su naturaleza, en sus efectos y en sus causas. El manuscrito no fue publicado en vida de su autor y conoció el honor de volverse libro gracias a un esfuerzo de investigación y edición del Instituto Caro y Cuervo, en 2002 $2^{10}$; fue su hijo, Miguel Antonio Caro, que organizó, en 1873, una compilación de su variada obra y dejó vislumbrar algunos escritos juveniles de su padre, cuando éste aún no se insinuaba siquiera como uno de los fundadores del Partido Conservador colombiano $^{11}$. La transcripción comentada del manuscrito de 1836, 166 años después, estuvo a cargo de la filósofa Esther Juliana Vargas Arbeláez y su noticia preliminar contiene equívocos que corrigió y superó con creces la investigación posterior, de 2011, de un estudiante de la Maestría en Historia de la Universidad Nacional de Colombia, cuyo nombre es Carlos Rubén Gélvez $^{12}$. La filósofa reprodujo, sin mucho examen, lo que había alcanzado a decir, en 1964, el ya clásico libro de Jaime Jaramillo Uribe, El pensamiento

${ }^{9}$ (Rosanvallon, 2003, p. 25).

${ }^{10}$ (Caro, 2002 [1836]). La transcripción, las notas editoriales y una noticia preliminar estuvieron a cargo de Esther Juliana Vargas; varias de sus notas a pie de página son glosas que incurren en la anacronía, como aquella en que asocia algunas ideas del estudiante neogranadino con unos postulados de Edmund Husserl; en otras, simplemente hay incuria para adjudicar autoría u origen de algunas citas, como en el epígrafe de Felicité de Lamennais que, en realidad, proviene de su Essai sur l'indifférence de 1823 (Caro, 2002, [1836], p. 179). El libro cuenta con otro estudio preliminar a cargo de Germán Vargas Guillén que es una interesante tentativa de interpretación de lo que se conoce como los Escritos filosóficos (Caro, 1954), además de su Mecánica social. La edición señala los folios del manuscrito original y reproduce algunas páginas facsimilares.

${ }^{11}$ Es necesario advertir que no nos interesa enfatizar ni sugerir asociaciones de este manuscrito juvenil con el futuro próximo de su autor. Una ilusión en la interpretación de lo que alguien pensó en un momento determinado de su existencia, es asociarlo con una imaginada coherencia; como si eso que hubiese pensado guardase algún tipo de conexión o de anticipación con respecto a decisiones posteriores. Véase: (Skinner, 1969, 1, pp. 3-53).

${ }^{12}$ (Gélvez, 2011). El título de la tesis se desliza en la anacronía que acabamos de advertir; aun así, la investigación de Gélvez esclarece el vínculo de afinidad del estudiante Caro con la obra de François-Louis-Charles Comte; tal vez lo único reprochable es que no hubiese empleado de este autor una edición original en francés, sino una traducción al español. 
colombiano en el siglo XIX, sobre la presunta filiación positivista comteana del joven estudiante José Eusebio Caro ${ }^{13}$. Lo que había dicho Jaramillo Uribe no tenía el apoyo documental del manuscrito publicado décadas después $\mathrm{y}$, curiosamente, la filósofa que preparó la edición de los desempolvados papeles del estudiante Caro se apegó sin cautela al lejano dictamen del pionero de la historiografía profesional en Colombia.

En contraste, el joven historiador Gélvez aprovechó mejor la novedad de un manuscrito intrincado, repleto de reiteraciones, vacilaciones y enmiendas. Son varios los aciertos de Gélvez que permiten dilucidar cualquier camino interpretativo posterior. Destaco por ahora dos: primero, sugiere ver aquel librito como testimonio de las ideas que circulaban por aquellos años en los recintos universitarios bogotanos; segundo, es contundente al demostrar que el Comte de los apuntes de Caro no es Auguste Comte (1789-1857), conocido como el fundador del positivismo, sino François-Louis-Charles Comte (1782-1837), autor de Tratado de legislación o exposición de las leyes generales con arreglo a las cuales prosperan, decaen o se estancan los pueblos, cuya edición original en francés data de 1826 y que, según Gélvez, ya circulaba traducción española en la década de $1830^{14}$.

Ahora bien, la perplejidad de estos primeros pasos queda plasmada en el quid pro quo del historiador Francisco Ortega en un ensayo que escribió en 2015. Ortega debió haber leído a las volandas el hallazgo de Gélvez, porque en un pasaje de su ensayo habla de Auguste Comte, pero en la referencia al pie de página hace la atribución al otro Comte, al Comte descuidado por los pocos historiadores y filósofos que habían hecho algunos escarceos en el estudio del pensamiento colombiano del siglo $\mathrm{XIX}^{15}$. El historiador

${ }^{13}$ No sobra recordar que el libro de Jaime Jaramillo Uribe es el resultado de una investigación que culminó en Alemania en 1956; por tanto, el corpus documental al que tuvo acceso fue mucho más limitado si se compara con los avances archivísticos de tiempos recientes. El vínculo con el positivismo de Auguste Comte lo hace en el capítulo XII de su libro (Jaramillo Uribe, 1964, pp. 181-204).

${ }^{14}$ Advertimos a los lectores de este ensayo que haremos traducción libre del original en francés, Traité de Législation, ou exposition des lois générales suivant lesquelles les peuples prospèrent, dépérissent ou restent stationnaires (Sautelet et Compagnie, Paris, 1826) ; la primera edición en español data, más precisamente, de 1827.

${ }^{15}$ Es decir, habla de unas ideas de Auguste Comte, pero en una nota al pie de página las atribuye a François-Louis-Charles-Comte; véase: Francisco Ortega, "República, tiempo incierto y moral en la primera mitad del siglo XIX” (Ortega, 2015, pp. 335-349). La página 345 (en dos notas a pie de página) de su ensayo revela una confusión sobre la novedad que aportaba, para entonces, la investigación de Gélvez, o un apego al equívoco de atribuirle a Caro un vínculo con la obra de Augusto Comte. Aparte de esta confusión, el ensayo Ortega informa una apreciación correcta acerca del proyecto del joven Caro de proponer una ciencia de la moral. 
Ortega, a pesar de su bien intencionado ensayo, incurrió en una pifia que hizo notar que todavía estamos en un punto indeciso de una disciplina que intenta tomar todas las precauciones necesarias para decir algo inteligible sobre la historia del pensamiento colombiano.

Pero volviendo al manuscrito intrincado del joven estudiante José Eusebio Caro y teniendo en cuenta lo que Gélvez esclareció, emprendamos nuestro propio ensayo de interpretación.

\section{EI método analítico aplicado al estudio de la sociedad}

El manuscrito del joven de 19 años no es, por supuesto, la exposición rigurosa y completa de un sistema de pensamiento o algo semejante; sin embargo, contiene afirmaciones que sugieren una tentativa por decir algo, y eso no lo puede desechar una historia del pensamiento. Dicho de otro modo, estamos ante un libro fallido, pero la tentativa tiene significación. Los tanteos del estudiante Caro pueden decir mucho acerca de las intenciones del autor o de lo que pretendía hallar. Y, más aún, puede decir mucho acerca de lo que buscaban resolver, en aquel tiempo, individuos como el joven estudiante de Filosofía y Jurisprudencia.

Desde las primeras líneas, Caro anuncia el propósito, el objeto y el método:

"El que quiere aprender la ciencia del cielo, sale al campo, y comienza por observar la apariencia general que le presenta el cielo: el que quiera aprender la ciencia de las sociedades, salga a la plaza, y comience por observar la apariencia general que le presentan las sociedades" (Caro, 2002 [1836], p. 123).

El propósito y el objeto parecen novedosos: "aprender la ciencia de las sociedades"; el siglo XVIII había terminado entregado a la observación de la naturaleza. Esta vez, el lente de la ciencia tomaba al hombre como objeto; "el hombre: esto es lo que donde quiera veremos pasar por delante metamorfoseado bajo mil formas" (Caro, 2002 [1836], p.124). La novedad, presumo, no es solamente observar al hombre y volverlo objeto de una ciencia, "la ciencia de las sociedades"; la novedad es, también, que el observador "salga a la plaza". El pretendido científico de la sociedad debe salir a la calle, atravesar "de polo a polo a una ciudad cualquiera" (y no hablemos aún del hallazgo) para que pueda decir que la certidumbre de su observación está ratificada por la percepción sensorial: "lo hemos visto con nuestros ojos, lo hemos escuchado con nuestros oídos, lo hemos palpado con 
nuestras manos" (Caro, 2002 [1836], p.128). De modo que la satisfacción de los sentidos se unía a las pruebas que dotaban de veracidad el hallazgo.

El joven estudiante había acudido a un método que le permitía ver, escuchar y palpar "la apariencia general que le presentan las sociedades" (Caro, 2002 [1836], p. 123) hasta aprehender el "hecho más aparente en toda sociedad" (Caro, 2002 [1836], p. 139). Ese método era conocido como el método analítico; aplicado extensamente en la observación de la naturaleza con el fin de hallar regularidades que permitiesen establecer leyes, el método analítico fue llevado a la observación de la sociedad. Durante los primeros decenios del siglo XIX, tal método era, para algunos, casi un dogma, la única manera de llegar al conocimiento de la verdad, tanto en el mundo natural como en el mundo social. Según François-Charles Comte (el Comte que sí había adoptado en detalle el joven Caro), el método analítico aplicado a una pretendida ciencia del hombre era una derivación feliz de su aporte al estudio de los hechos naturales. Su eficacia en el hallazgo de la verdad residía, según su Traité de législation, en que era un método alejado de cualquier opinión particular o de un sistema de ideas previo, "porque los juicios no se forman más que a la medida en que se avanza en el estudio de los hechos" (Comte, 1826, t. 1, p. 13). No se partía de premisas, ni de sistemas de ideas, ni de opiniones para ser comprobados o refutados con el recurso de la observación; simplemente era observar los hechos, "clasificarlos en el orden más natural" hasta hallar regularidades que pudiesen plasmarse en leyes o en teorías (Comte, 1826, t. 1, p. 2). Ese camino, que Comte y otros juzgaron productivo en las ciencias naturales, podía trasladarse al estudio de la sociedad humana para cimentar, a juicio del autor francés, las ciencias de la legislación y de la moral (Comte, 1826, t. 1, p. 18); aún más, aplicando rigurosamente el método de observación, descripción y clasificación de los hechos, las ciencias de la moral y de la legislación podían hacer parte de "la historia natural del hombre" (Comte, 1826, t. 1, p. 18).

¿Cuál fue el hallazgo de Caro en su observación de la ciudad? "Un inmenso montón de hombres en movimiento incesante" (Caro, 2002 [1836], p. 124). Sin embargo, en su método y su hallazgo asoma una advertencia. Para poder llegar a una afirmación más general que incluya todas las sociedades humanas del orbe, Caro admitió que el procedimiento de salir a caminar por la capital de la Nueva Granada suministraba información insuficiente. Caro, igual que su maestro Comte, reconoció que el método de la observación directa no bastaba porque la índole de su objeto de estudio no es la misma de aquellos que provienen del mundo natural. La distinción de los objetos de estudio se hizo, entonces, necesaria. Comte había advertido que el estudio de los hechos sociales era mucho más difícil que el estudio de 
los hechos naturales; "el físico -señaló Comte- es amo de la materia sobre la cual hace sus experimentos", y más adelante advertía que las ciencias morales y políticas "no disponen de los pueblos como los químicos disponen de la materia" (Comte, 1826, t. 1, p. 19). Caro, posiblemente siguiendo a Comte, admitió que la observación y la percepción sensorial proporcionaban datos incompletos sobre los hechos sociales; por tanto, juzgaba necesario acudir al complemento de la prueba testimonial. Aunque Comte fue más prolijo en explicar los alcances y variedades de la prueba testimonial, en que incluyó relatos de viajeros y de historiadores, Caro terminó concediéndoles igual aporte a la observación y al testimonio para llegar a "una misma verdad: el hombre móvil" (Caro, 2002 [1836], p. 131).

Luego del hallazgo de "una acción continua" en la sociedad, el joven estudiante se concentró enseguida en el instrumento de la clasificación. Primero observó "la apariencia general que le presentan las sociedades" (Caro, 2002 [1836], p. 123); luego halló que "el hecho más aparente en toda sociedad es el hombre en movimiento" (Caro, 2002 [1836], p. 139); después advirtió que "para poder penetrar hasta las causas del movimiento humano" era indispensable el instrumento de la clasificación (Caro, 2002 [1836], p. 141). Sin embargo, era menester saber clasificar, "formarnos una idea clara de los principios" de la clasificación de los movimientos. El joven Caro tomó muy en serio el procedimiento de clasificación de los movimientos humanos; en el trunco libro es el apartado más minucioso, el más extenso, el más repetido. La insistencia en el asunto delata inseguridad o incertidumbre, pero también pudo ser la necesidad de fijar en suelo firme la tarea siguiente, quizás la más trascendente por ambiciosa. Es ostensible que el autor quiso detenerse en las causas de los movimientos voluntarios, lo que le despejaba el camino para exponer su teoría de la voluntad.

A partir de este punto la obra se resquebraja en escarceos de planes de un libro que no conoció culmen. A pesar de ese defecto, la obra se vuelve más rica en datos para nuestro examen. Su intención fue escribir una teoría de la voluntad, porque el estudio de las acciones humanas debía desembocar en una ciencia de la moral y en una ciencia de la legislación. Su tentativa lo llevó a enlazar su estudio de la voluntad con las ideas de posesión, libertad, derecho, deber y todo esto lo conectó luego con aquellas sobre la producción de riqueza, el intercambio de mercancías, la división social del trabajo. En definitiva, su análisis del movimiento humano le mostró una sociedad compuesta de un circuito de continuos intercambios.

Pobre en originalidad y rico en apego a tradiciones, el libraco parece rendirle homenaje a Antoine-Louis-Claude Destutt de Tracy a la vez que intenta sostener una conversación crítica con la obra de Jeremy Bentham; el 
esquema para demostrar el nexo entre la voluntad y la producción de ideas evoca los postulados de por lo menos los cinco primeros capítulos del primer tomo de Éléments d'Idéologie, consagrado a "la ideología propiamente dicha". La conexión entre las sensaciones, la memoria, los recuerdos, los juicios, la voluntad y el movimiento la expone y explica casi en el mismo orden argumentativo del pensador francés. Aquí vale la pena citar a Caro en extenso:

"Está reconocido que nuestros recuerdos vienen de nuestras sensaciones o
percepciones; que nuestros juicios nacen de nuestros recuerdos, y sensa-
ciones o percepciones; que nuestros deseos vienen de nuestros juicios; que
nuestras voliciones vienen de nuestros deseos y de nuestros juicios; que
nuestras acciones vienen de nuestras voliciones. Tal es la generación de
nuestras ideas" (Caro, 2002 [1836], p. 189).

El estudiante neogranadino parece haber adoptado una explicación sensualista para vincular una teoría de la voluntad con, primero, una teoría del conocimiento y, luego, con una teoría de la acción cuyo desenlace más consecuente era una disquisición sobre libertad, derechos y deberes; y, otra vez hay que decirlo, el orden expositivo del estudiante se asemeja a un ejercicio escolar de aplicación del esquema argumentativo de, en esta ocasión, las partes IV y V de los Éléments d'idéologie, consagradas a un "tratado de la voluntad y sus efectos". Incluso, en algunos pasajes hay reproducción literal de afirmaciones tales como "la libertad es [...] el poder de ejecutar nuestra voluntad", cuya procedencia más inmediata es la obra de Destutt de Tracy (Destutt de Tracy, 1804, p. 269; 1818b, pp. 98-126) ${ }^{16}$. Las semejanzas se extienden a la definición de utilidad que implicó discutir en el camino con la obra de Bentham y llegar hasta el entronque con algunas nociones básicas de economía política en que las obras de Adam Smith y de Jean-Baptiste Say adquirieron relieve. Aquí es notorio el desenlace trunco de la obrita de Caro, pero alcanzó a insinuar un plan temático en que destacaba nociones tales como valor, utilidad, propiedad, intercambio de bienes.

¿Qué adquiere significado para una historia del pensamiento cuando hallamos evidentes o tácitos vínculos con autores y obras? Caro enunció en su libraco una biblioteca de autores leídos, aplicados, discutidos y, en pasajes, reproducidos. Eso hizo con Comte (el del Traité de législation), Destutt de Tracy, Bentham, Jean-Baptiste Say, Helvetius (a quien llamó

${ }^{16}$ La idea de libertad de Destutt de Tracy está, a su vez, atada a la obra de John Locke; evocando a éste, el filósofo francés dice que la libertad es « la puissance d'exécuter notre volonté ». 
“el Newton de la moral y la legislación”). Cuando habló del hábito y del instinto remitió a las obras de Maine de Biran, Cabanis y Broussais. Salvo la excepción ilustre de Bentham, el joven Caro estaba embelesado con el grupo de los ideólogos y los médicos fisiólogos franceses.

Sin embargo, destacar un inventario de lecturas atribuibles en la reflexión incipiente de un estudiante neogranadino de 19 años es, apenas, dato anecdótico; el significado de ese inventario es la participación, así sea subordinada, en una comunidad de pensamiento que había entronizado en el estudio del hombre un método -el analítico-, un objeto de estudio -el "movimiento incesante" de la sociedad; y, finalmente, un propósito: "escribir una ciencia" (Caro, 2002 [1836], p. 241). Lo único posible que podía surgir de un modo de investigar en la sociedad era un conjunto de juicios que resultasen de la "observación escrupulosa" que Charles Comte y Destutt de Tracy ya habían elogiado como el método más eficaz para llegar a juicios por vía de la inducción; y el "hallazgo" de nuestro joven Caro era algo que, también, aquellos dos pensadores ya habían detectado. De modo que el punto de llegada del "descubrimiento" de Caro era algo que, por lo menos dos decenios antes, ya era el punto de partida de Destutt de Tracy, el movimiento humano ${ }^{17}$.

"Hemos sentado las bases de una ciencia" que consistía en "la descripción de los hechos humanos generales; la descripción general de los efectos de cada uno de estos hechos. Esto es moral. Esto es una ciencia" (Caro, 2002, [1836], p. 236). El entusiasmo juvenil de Caro no disminuye la trascendencia de esta intención; volver ciencia algo que estaba situado en un lugar en que se confundía "con la reprobación, aprobación y opinión popular, con la ley, y con la religión divina" (Caro, 2002, [1836], p. 237). José Eusebio Caro intentó llegar a este punto con la ayuda de un método afamado por el prestigio de autoridades y, sobre todo, animado por eso que podríamos llamar una conversación de época en que la apuesta fundamental era procurar los cimientos y hasta los deslindes de unas pretendidas ciencias en que el ser humano fuese su objeto. Ese es, quizás, el significado más prominente del listado de autores que el estudiante Caro y, por supuesto, sus maestros en Santafé de Bogotá estaban leyendo y discutiendo como lo testimonia el esbozo de libro que tenemos entre manos.

${ }^{17}$ Destutt de Tracy, en el tomo tres de sus Éléments d'idéologie, consagrado a la lógica, dijo: «Le monde n'est composé pour nous que des accidents et des phénomènes résultants du mouvement »; más adelante, hablando de las bondades del método analítico concluirá : « L'unique cause universelle de toutes les autres, c'est le mouvement » (Destutt de Tracy, 1818a, pp. 389, 571). 


\section{Prolegómenos de unas ciencias del hombre}

El joven estudiante neogranadino se había propuesto conferirle a la moral el estatuto de una ciencia, separarla de preceptos y admoniciones; el salto del afán preceptivo de cualquier religión al afán descriptivo de una ciencia fundada en la observación y la clasificación colocaba a Caro en una tentativa secularizadora; pero su tentativa, por supuesto, no era nueva ni solitaria. Daba un paso adelante para colocarse a tono con una discusión que entretenía a una comunidad de individuos que, por lo menos desde mediados del siglo XVIII, enfatizaba los vínculos indisolubles entre el mundo natural y el mundo social. Más aún, trasladaba al estudio de las sociedades humanas el método que había permitido establecer leyes de funcionamiento del mundo físico, describir y clasificar especies animales y minerales.

Que la pretendida ciencia moral fuese definida como una ciencia de observación, "como todas las otras", delata unos vínculos de afinidad y una necesidad de legitimación de unos procedimientos; dicho de otro modo, el jovencito Caro estaba inmiscuyéndose en un campo epistemológico, en una tradición de conocimiento que puede remontarse, por lo menos, a ciertos postulados de la Ilustración en que el hombre devino objeto de estudio. Antes de esta audacia juvenil de Caro, otros pretendidos "científicos" o "sabios", en lo que había sido el virreinato de la Nueva Granada, habían acudido al mismo método y lo habían exaltado con vigor. Ese fue el caso de Francisco José de Caldas, según sus memorias de geografía registradas en el Semanario del Nuevo Reyno de Granada, en 1808; el "sabio" Caldas recordaba, en ese entonces, que las regularidades halladas en la relación de los seres humanos con el medio geográfico eran resultado de la experiencia $\mathrm{y}$, sobre todo, de trasegar por ríos, montañas y valles "siempre guiados por la antorcha de la observación" (Caldas, 1808, 22, p. 202). Casi treinta años después, José Eusebio Caro tomó la misma antorcha y observó al hombre, pero esta vez en la ciudad. Caldas y Caro son dos puntos de manifestación de un mismo método y, sobre todo, de una misma pretensión: volver ciencia el estudio del hombre.

Cuando digo que José Eusebio Caro quedó inmerso, así fuese de un modo muy subordinado, en una conversación de época, nos referimos a que su librejo puede situarse en un proceso de construcción de lo que otros llamarán un campo epistemológico que buscaba distinguir y legitimar una o varias ciencias cuyo objeto era el hombre. El punto de partida para los participantes en ese debate es que "todos los fenómenos de la naturaleza están ligados unos a otros de tal forma que es imposible separarlos sin ejercer 
una especie de violencia" (Comte, 1826, p. 31) ${ }^{18}$. Por eso, la solución más tranquila era poner al hombre dentro de los objetos de observación de una historia natural; Destutt de Tracy advirtió que su ideología debía entenderse como "una parte de la zoología" que se encargaba de observar al hombre "comme animal ayant des facultés intellectuelles" (Destutt de Tracy, 1804, p. IX). Charles Comte -ya lo hemos dicho- se propuso unir las ciencias de la legislación y la moral a "la historia natural del hombre". El otro Comte -el más conocido para nosotros- no era nada ajeno a la conversación; su propósito de constituir la "física social" pasaba por observar "todos los fenómenos sometidos a unas leyes naturales invariables" y, por tanto, consideraba indispensable apoyarse en un acumulado de observaciones directas del funcionamiento de los órganos del cuerpo humano, y ese conocimiento lo proporcionaba la fisiología (Comte, 1829, p. 58) ${ }^{19}$.

En el año 1800, en París, un grupo de naturalistas, filósofos, médicos, publicistas, arqueólogos, botánicos, historiadores, economistas, lingüistas, exploradores decidieron aglutinarse en la Société des Observateurs de 1'Homme. Mientras la asociación la presidía el botánico Antoine-Laurent de Jussieu (1748-1836), el programa de acción de la asociación fue emprender "la historia natural del hombre"20. A pesar de las disímiles proveniencias, aceptaron en principio que, en el estudio del hombre, lo físico y lo moral eran indisociables. Aquellos que han estudiado aquel momento asociativo de los científicos franceses destacan y discuten lo que los impulsó a asociarse. Son años de auge de expediciones con ánimo colonialista en busca de recursos naturales para los países europeos; los científicos hacían su aporte con la descripción y clasificación de plantas, animales y seres humanos. Los reunía la intención de volcar sus experiencias investigativas en el mundo natural al estudio de los comportamientos humanos; el método empírico triunfante

${ }^{18}$ En el original en francés : « Tous les phénomènes de la nature sont tellement liés les uns aux autres qu'on ne peut les séparer sans une espèce de violence ",

${ }^{19}$ Aunque convengamos en que el vínculo de Caro con la obra de Charles Comte es evidente, no desestimamos que los postulados de Auguste Comte fuesen del todo ignorados por la comunidad de profesores y estudiantes de Derecho de las universidades neogranadinas; menos podemos ignorar que sus postulados pertenecían al mismo campo de afinidades, sobre todo en la importancia concedida a la fisiología como presunta vía de observación directa de las funciones intelectuales del ser humano.

${ }^{20}$ Destaquemos que Jussieu fue maestro de Francisco Antonio Zea; tengamos en cuenta que Zea, muy probablemente, fue al menos espectador de este hecho de sociabilidad científica mientras residió en París bajo la tutela del botánico Jussieu. En 1802, Zea envió su propuesta de reorganización de la expedición botánica, quizás inspirado en la organización del mundo científico en Europa. 
en las expediciones científicas dio sustento para que el naturalismo sirviese de guía en la observación y descripción del hombre ${ }^{21}$.

Dicho de otro modo, en el umbral de cambio de siglo, el mundo científico dirigió su mirada al hombre y quiso volverlo su objeto; para hacerlo, acudió a dos legados metodológicos inmediatos que ya suministraban información, discutible o no, acerca de los comportamientos humanos: de un lado, la experiencia en observaciones y descripciones de los naturalistas, incluso algunas cuestionadas y tendenciosas clasificaciones raciales; del otro, los hallazgos de los fisiólogos que se habían dedicado a validar las premisas sensualistas y que parecían ofrecer las primeras explicaciones en torno a las facultades cognoscitivas y afectivas de los seres humanos. De tal manera que cualquier tentativa de construcción de un campo de estudio antropológico o psicológico o moral estaba obligada a partir de las supuestas evidencias de observación directa de los fenómenos. Por eso, en 1800 y años más adelante era inevitable acudir a las obras de Helvetius, Cabanis, Maine de Biran cuando se trataba de hablar de la organización del hombre como "animal con facultades intelectuales".

La ideología, que era el esfuerzo por reconstituir los mecanismos de formación de las ideas, le debió mucho a aquella asociación científica fundada en París y más aún al legado sensualista de un Helvetius y su $D e$ l'Esprit (1758) o de un Condillac y su Essai sur l'origine des connaissances humaines (1777). Helvetius, elogiado en su momento por Bentham porque había puesto a circular la noción de interés como el equivalente de utilidad, había afirmado que las causas productoras de las ideas eran la sensibilidad física y la memoria; Condillac, a su vez, había juzgado indispensable que todo sistema de gobierno debía basarse en el estudio de los hábitos y costumbres de cada pueblo. Pero, sin duda, la obra de impacto más inmediato en la misma Société des Observateurs de 1'Homme y en los fundadores de la ideología, entre ellos, por supuesto, Destutt de Tracy, fue la del médico Pierre Cabanis, autor de Rapports du physique et du moral de l'homme

${ }^{21}$ El listado más aproximado de sus miembros es: Naturalistas: Cuvier, Jauffret, Jussieu. Linguistas: Destutt-Tracy, de Gérando, Le Blond, Massieu, Sylvestre de Sacy, Sicard, Itard. Filósofos: Laromiguière, LeMoreau, Moreau, Garât. Eclesiástico: Jauffret. Médicos : Bouvyer-Desmortiers, Bojanus, Cabanis, Duméril, Guillon-Pastel, Halle, Lassus, Moreau de la Sarthe, Nysten, Thouret, Sue. Exploradores: Andrew, Baudin, Bernier, Bougainville, Bissy, Hamelin, Legout, Levaillant, Maugé, Michaux, Riedlé, Sonnini. Arqueólogos, historiadores, economistas: d'Ansse de Villoison, Bouchaud, Clermont-Lodève, Larcher, Marcel, Millin, Papon, Pastoret, Pfeffel, Portalis, Sainte-Croix, Volney, Walckenaer. Helenistas: Coray, Ricard (d'Ansse de Villoison). Publicistas: Bonnefoux, La Chaussée, Lerminier, MathieuMontmorency, Haller. Véanse al respecto : (Chappey, 2000, pp. 47-54), (Azouvi. 1984, pp. 151-170), (Jamin, 1979, pp. 313-335), (Blanckaert, 2000, pp. 117 - 160). 
(1802). Fue esta memoria científica de Cabanis la que puso a gravitar cualquier ensayo de ciencia del hombre en torno al hecho fisiológico. Desde Cabanis hasta François-Joseph-Victor Broussais y su De l'irritation et de la folie $(1828)^{22}$, la medicina y más exactamente la fisiología tuvieron el mando en cualquier explicación orgánica de los sentimientos, emociones e ideas de los seres humanos. Los Éléments d'Idéologie, cuyos varios tomos salieron entre 1802 y 1808 , parecieron consagrar el dato fisiológico como premisa para cualquier desarrollo de las ciencias morales y legislativas, para los rudimentos de ciencias del hombre que parecía orientarse hacia la antropología, la psicología y, en la terminología del Cours de Philosophie positive, hacia la física social.

El juvenil Caro, al seguir el esquema expositivo de Destutt de Tracy, y al mencionar los nombres de Cabanis y Broussais, estaba poniendo su fallido libro en la autoridad jurisdiccional de la fisiología médica francesa que, a su vez, sometía cualquier idea acerca del hombre a la causalidad física, a la explicación de las funciones de los órganos del cuerpo. Téngase muy en cuenta que Cabanis, en su obra de 1802, elogió los Éléments d'idéologie de Tracy por haberse apoyado en los hallazgos de la fisiología del cuerpo humano; según este célebre médico francés, "las operaciones de la inteligencia y la voluntad se confundían, en sus orígenes, con los demás movimientos vitales", de tal manera que "los principios de las ciencias morales entrarían en el dominio de lo físico; ellas no serían más que una rama de la historia natural del hombre" (Cabanis, 1815, pp. XIV y XV). En 1828, cuando asomaba el debate con el espiritualismo o eclecticismo de Victor Cousin, basado en muy buena medida en la lectura y difusión de los hallazgos de François-Pierre Maine de Biran, el médico Broussais exaltó otra vez "la poderosa influencia de las vísceras sobre el pensamiento" y recordó con orgullo que fueron los hallazgos de la fisiología y la medicina los que les permitieron "el derecho exclusivo de dictar las leyes a la ideología" (Broussais, 1828, p. 223) 23 .

He aquí, entonces, dónde y cómo se sitúa el fallido librito del estudiante José Eusebio Caro; quién sabe con qué grado de lucidez hizo adhesión a lo que hoy suele denominarse el "momento naturalista" de las ciencias humanas; un momento en que las ciencias humanas, para poder empezar

${ }^{22}$ El título de esta obra era, en extenso, el siguiente: De l'irritation et de la folie. Ouvrage dans lequel les rapports du physique et du moral sont établis sur les bases de la médicine physiologique.

${ }^{23}$ A propósito del debate con el "psicologismo" animado por Victor Cousin, véase : (Azouvi, 1984, pp. 151-170). Estudios más recientes: (Braunstein, 2012, pp. 197-212), (Baetschi, 2005, pp. 451-463), (Barbara, 2012, pp. 213-236). 
a decir algo, tomó préstamo de métodos y hallazgos de la historia natural, de la física newtoniana, de la medicina; en fin, manera sumisa de buscar su propio lugar.

Resta, enseguida, saber explicar por qué un estudiante neogranadino estaba inmiscuido en búsquedas tales. Creemos que él participaba de una definición de prioridades que tenían un sello institucional; por algo él escribió este sustancioso batiburrillo mientras era estudiante de Filosofía y Jurisprudencia; por algo sus maestros tenían como autores de cabecera a Destutt de Tracy y Bentham; por algo estaba intentándose escribir, en esos años, en la Nueva Granada (hoy Colombia), códigos de policía, códigos penales, manuales de administración pública, manuales de derecho constitucional. Internémonos en las condiciones de posibilidad que ayudan a explicar por qué a Caro se le ocurrió escribir esta obra inconclusa.

\section{La razón de Estado}

En este punto es forzosa una advertencia de método. Vamos a salir del texto de Caro, vamos a ir a eso que solemos llamar el contexto. Hasta aquí hemos hablado acerca de lo que dice y cómo lo dice; también hemos acudido a la intertextualidad, a la biblioteca intelectual sugerida por el propio autor. Esta vez se impone indagar cuáles fueron las condiciones intelectuales que hicieron posible la motivación y la intención del joven escritor, y eso nos obliga a averiguar qué estaba discutiéndose en la época, qué había en el lenguaje público de la entonces Nueva Granada; se vuelve importante saber quién hablaba en ese esbozo de libro, cuál era el lugar social de su enunciación, dónde y cómo estaba situado el joven autor. En consecuencia, intentaremos poner en relación lo enunciado por el estudiante Caro con "un campo adyacente" de otros enunciados. Dentro de ese campo de enunciados, Caro y su bosquejo de libro debieron ocupar un lugar; pero para saber precisar su situación, se vuelve necesario, antes, tener alguna idea de lo que estaba discutiéndose en ese campo ${ }^{24}$.

El año 1836, fecha que aparece en el manuscrito del estudiante del Colegio San Bartolomé, fue momento de intenso cuestionamiento de la enseñanza de la obra de Jeremy Bentham en los recintos universitarios de

${ }^{24} \mathrm{El}$ contextualismo en historia del pensamiento es algo laboriosamente establecido por autores como Michel Foucault, en su método arqueológico (Foucault, 1969); por Mijail Bajtin, al afirmar que "todo enunciado concreto viene a ser un eslabón en la cadena de la comunicación discursiva" (Bajtin, 1982, pp. 257; 258). Algo muy semejante propuso Quentin Skinner cuando dijo que todo "acto de comunicación constituirá siempre la asunción de determinada posición en relación con alguna conversación o argumentación preexistente" (Skinner, 2002, p. 115). 
la Nueva Granada. Hay historiografía reciente respetable que habla de este segundo momento de lo que ya acostumbra designarse como "la querella benthamista" 25 . Discutir con esa historiografía ahora no es oportuno, basta por ahora decir que compartimos muchos de sus hallazgos y trazos interpretativos de aquel lapso histórico, pero juzgamos que esa misma historiografía omite la sustancia de lo que, suponemos, estaba en liza.

Lo que se conoce como la querella benthamista parece una discusión concentrada en la enseñanza de los principios de legislación universal de Jeremy Bentham por considerarlos, según la alarma de los padres de familia, "perjudiciales a la instrucción moral y religiosa de sus hijos" (Torres, 1836, p. 3$)^{26}$. Desde 1835 , obispos, sacerdotes, deanes, directores de colegios, padres de familia y varios senadores le pedían al gobierno de Francisco de Paula Santander que suprimiese los textos del inglés porque los juzgaban "en total contradicción con los dogmas sagrados de la Religión Christiana" (Varios, 1835, p. 2). Aquel anti-benthamismo incluyó lamentos por la abolición del tribunal de la santa inquisición (1821); puso en duda tanto las obras de Bentham como las de Charles-Jean Bonnin, porque "no merecen la calificación de obras clásicas, ni son completas, ni sus principios son conformes a la moral natural, ni a la religión católica" (Mosquera, 1836, p. 3$)^{27}$. Unos ampliaron la crítica a las bases sensualistas del utilitarismo y cuestionaron a Epicuro, Cabanis, Destutt de Tracy -"la nueva escuela de materialismo que ha enlutado la Europa" (Mosquera, 1836, p. 24) -. Otros propusieron dejar "a un lado esa impertinente alegoría aritmética, patológica, dinámica apurada hasta el extremo del ridículo" (Torres, 1836, p. 19). En fin, Bentham, el utilitarismo, los vestigios de la ideología y del fisiologismo fueron juzgados a la vez como subversivos e insuficientes. Subversivos, porque estaban "en total contradicción con los dogmas de la Relijión Christiana" (Varios, 1835, p. 2); insuficientes, porque descuidaba factores específicos como la raza, el clima, la clase social. Ante su insuficiencia,

${ }^{25}$ Hubo un primer momento entre 1826 y 1828, asociado con la conspiración contra Simón Bolívar, y una tercera polémica en la década 1860, como si el pensamiento político y los conflictos entre la élite colombiana hubiesen permanecido intactos. Peor aún, como si el Estado en Colombia hubiese tardado mucho en definir e imponer su monopolio simbólico.

${ }^{26}$ Respetamos en este ensayo la grafía de la época.

${ }^{27}$ Aunque admitimos que la polémica estuvo concentrada en la obra de Jeremy Bentham, no puede despreciarse que se incluyera, en los ataques, la obra de Bonnin que, por entonces, significaba una relativa renovación de los estudios sobre administración pública y, por supuesto, en la enseñanza de derecho administrativo; su influjo fue reconocido por Florentino González en sus Elementos de ciencia administrativa (1840). Destacamos algunos estudios al respecto: (Martínez Rodríguez, 2014), (Dávila, 2007). Aunque detenido en otra coyuntura, aporta una interesante mirada foucaultiana sobre este tipo de debates en el siglo XIX colombiano: (Saldarriaga Vélez, 2004). 
alguien sugirió incorporar en la enseñanza del Derecho la lectura de, por ejemplo: el Comte del Tratado de legislación, cuyo juicio adverso sobre Bentham fue bien usado por los anti-utilitaristas granadinos; el tratado de Gentillet contra Maquiavelo, cuyas obras completas ya circulaban en la Nueva Granada o, por lo menos, eran de interés para el general Santander; el debate de Leibniz y Barbeyrac condensado en El juicio de un anónimo; los tratados de Cicerón y Montesquieu; y -ioh, sorpresa!- hasta admitió que se incluyese a Bentham, aunque no en la versión cuestionada de Ramón Salas. En fin, la discusión parecía algo más que impedir la obra de Bentham; se trató, mejor, de discutir los principios filosóficos y jurídicos "del orden social que debe hacer la dicha de la generación presente y de las generaciones futuras" (Mosquera, 1836, p. 19).

Sin embargo, la situación merece otras conjeturas. La enseñanza de las obras de Bentham, de Tracy, de Bonnin y de otros más hacía parte de un propósito de construcción de una ciencia de legislación que permitiera la unificación del lenguaje jurídico en unos códigos; por intermedio de las instituciones universitarias, de un cuerpo docente y de un pensum, el Estado buscaba concentrar el conocimiento jurídico y, quizás más impactante, elaborar el conjunto de códigos que eliminasen los múltiples derechos y jurisdicciones que provenían de los tiempos de la dominación española. Hacer del Estado una unidad cognitiva, simbólica, depositaria del poder de nombrar, legislar, codificar, ordenar. En consecuencia, poseedora de la suficiente fuerza unificadora, responsable de unas operaciones totalizadoras que, por consecuencia, eliminaban o erosionaban los variados derechos y potestades de corporaciones y estamentos. El Estado necesitaba producir su propia teoría sobre su necesidad de existencia y, al tiempo, determinar las operaciones básicas que lo hacían existir: los censos, las estadísticas, la cartografía, la codificación. A eso lo llama, cierta sociología, un proceso de concentración de todos los capitales (Bourdieu, 1993); para ser Estado tenía que provocar la ilusión -la ficción, dirá Pierre Bourdieu- de "producir el Estado" y los juristas, parece, eran los mejor capacitados para esa labor (Bourdieu, 1997).

La historiografía que habla de la "querella benthamista" suele despreciar el momento en que esa discusión afloró; era un momento drásticamente reorganizativo del Estado. Acababa de morir, en 1830, la república de Colombia como unidad política centralizada de lo que iban a ser, luego, Venezuela, Ecuador y la misma Colombia (lo que la historiografía hizo conocer como la Gran Colombia). Ese fracaso político y administrativo dejó un limbo legislativo y jurídico que debía resolverlo Santander que venía del exilio en Europa, causado por sus disputas con la facción política al mando 
del fallecido Simón Bolívar. La Constitución de 1832 lo invitó a regresar gloriosamente como presidente, en un desesperado esfuerzo por recomponer un Estado maltrecho, con una burocracia que no sabía a qué leyes debía obedecer, si a las antiguas heredadas del modelo español o a las que lograron sobrevivir, como especie de residuo, de la Constitución republicana de 1821 o a lo que empezaba a gestarse como nuevo Estado surgido de la penosa fragmentación de las élites de la inmediata post-independencia. Un abogado anónimo expresó así, en 1835, el malestar de muchos ante una situación embrollada luego de, según su balance, veinticinco años de acumulación confusa de unas leyes sobre otras:

\begin{abstract}
“AA dónde iremos a parar? Unas leyes derogan otras, otras las restablecen a su fuerza y vigor: unas derogan la mitad, y dejan vigente la otra mitad: unas derogan tal y tal artículo de tal ley y ratifican tal y tal, otras no preservan sino uno solo: unas refieren a tal y tal artículo que quedó vigente por la disposición del tanto de la ley de tal o cual fecha; de manera que en registrar referencias y libramientos se pasa el tiempo, se pierde la paciencia y se confunde el entendimiento ;Ah Babilonia en la que nos hallamos! Nadie sabe ya que es lo que rige, ni lo que está vigente" (Anónimo, 1835, p. 3).
\end{abstract}

Después de 1830, la prioridad era la reorganización del Estado y eso implicaba consagrarse a fabricar leyes en muchos ámbitos en una nueva tentativa de orden: para poner en cintura a los militares, había que redactar una ley orgánica del ejército, definir un tribunal disciplinario de lo militar; para deslindar el gobierno de la nueva unidad territorial, hacía falta una ley acerca del régimen político de las provincias, cantones y distritos; para cualquier litigio hacía falta un código de procedimiento civil; no había codificación en firme para castigar delitos mayores y menores. Peor, tal vez, se carecía de un sistema judicial; tampoco había un código de administración pública, no estaba reglamentado el acceso ni el ascenso en los empleos públicos; no había manuales de capacitación para el personal encargado del recaudo de impuestos. Para colmar tantos vacíos normativos, era necesario acudir a los abogados más expertos y cercanos al nuevo gobierno para encargarles, primero, la enseñanza del Derecho en las universidades; luego, ocuparlos en comisiones redactoras de los diversos códigos; por eso es que entre 1832 y 1839 nos hallamos ante un caudal legislativo de muy variado espectro; hubo leyes o, en el peor de los casos, proyectos de leyes y códigos de procedimiento civil, de policía, penal, de administración de justicia, sobre la composición y funciones de la Suprema Corte de Justicia; agreguemos a eso la redacción de manuales de derecho constitucional y 
derecho administrativo. Sin ánimo de exhaustividad, mencionemos algunos hitos de la codificación de esos años: Ley de procedimiento civil (1834), Ley orgánica de tribunales (1834), Proyecto de ley sobre juicios criminales menores (1836), Proyecto de ley que reglamenta establecimientos de castigo conforme al código penal (1836), Código penal (1837), Proyecto de ley orgánica del poder judicial (1838), Proyecto de ley sobre policía general (1839). En 1839, Cerbeleón Pinzón publica su primera edición del Tratado de ciencia constitucional; al año siguiente, Florentino González publica Elementos de ciencia administrativa. En suma, imposible no apreciar que los juristas estaban ejerciendo un papel unificador y, sobre todo, que eran ciertos juristas con ciertas concepciones de la ciencia de la sociedad los que ostentaban el atributo de ser los creadores de una codificación nacional que contribuía a la centralidad totalizante de un titubeante Estado y, al tiempo, consagraba a un personal que iba a ser reconocido como el poseedor o el principal detentador del lenguaje del universo jurídico ${ }^{28}$.

Hay unos documentos preciosos llamados "certámenes públicos" que informan acerca de las asignaturas y de los contenidos que los estudiantes de Filosofía y Jurisprudencia del Colegio San Bartolomé debían conocer y aprobar con solvencia. Esos certámenes dicen, por ejemplo, que, en 1834, Florentino González en calidad de catedrático de Derecho Público les pedía a sus estudiantes que disertaran acerca de la aplicación del principio de las recompensas a los sueldos de los empleados públicos (González, 1834, pp. 13-17). Al año siguiente, en la asignatura Derecho Civil, a cargo de Ezequiel Rojas, los estudiantes debían dar cuenta de su conocimiento de las leyes promulgadas un año antes acerca de organización de tribunales, de régimen político de las provincias, de procedimiento civil (Rojas, 1835, p. 9). El curso Principios de Legislación Penal y Política, a cargo también de Florentino González, tenía una parte consagrada a hablar de las necesarias leyes de policía como instrumento adicional de un código penal. El profesor de Filosofía, Isidro Arroyo, era el más comprometido con el modelo expositivo de la obra de Destutt de Tracy; sus pruebas de disertación estaban ceñidas a la tabla temática de "la ideología propiamente dicha". Por esos mismos años, los profesores del Colegio del Rosario estaban enseñando Legislación Universal con la aplicación del principio de "la utilidad general" para la legislación y de "la felicidad pública" como "objeto final de las leyes" (Duque Gómez, 1835, pp. 4-5).

${ }^{28}$ Aquí estamos próximos a una tentativa de socio-génesis del Estado cuyos detalles no podemos tratar en este ensayo; basta por ahora remitir a Bourdieu, 2012. 
En fin, ¿qué se nos vuelve evidente?, una afanosa producción y reproducción del Estado. El Estado estaba apoyándose en un grupo de juristas y catedráticos que le ayudaban a producir una ciencia de la sociedad, una teoría legislativa, unas definiciones acerca de la acción humana y de sus efectos en el mundo social, un discurso sobre la cosa pública. Todo esto debía plasmarse en una codificación más o menos homogénea en su doctrina y unitaria en sus alcances. He aquí -y es otra conjetura nuestrabuena parte del sentido del debate público de esos años conocido -más mal que bien- como "la querella benthamista". Estaba en discusión una ciencia moral deslindada de la preceptiva dominante del catolicismo; y estaba en discusión la selección del grupo de juristas y de sus doctrinas (por eso las sugerencias de tales o cuales autores y obras). Además, estaba en juego la capacidad universalizante, integradora, unificadora de un Estado que, en el proceso de acumulación del monopolio del capital jurídico ya había tenido un tropiezo con la fractura política de 1830, y de la cual intentaba restablecerse. En palabras de Michel Foucault, los funcionarios de Estado, empezando por el jefe del ejecutivo, el general Santander, hasta los estudiantes de Derecho, como lo era el joven José Eusebio Caro, intentaban contribuir a la expansión de la razón gubernamental; era un Estado que ansiaba tomar las riendas de un proceso cuyo objetivo más apremiante era "gobernar racionalmente porque hay un Estado y para que lo haya" (Foucault, 2006, p. 273). Era, en últimas, tratar de restablecer al Estado como "principio de inteligibilidad" (Foucault, 2006, p. 329).

Así creemos que hemos logrado precisar el lugar de enunciación del jovencito que estudiaba Filosofía y Jurisprudencia desde 1834 y que comenzó a escribir el batiburrillo de 1836. Él estaba participando, con su escrito, de un hecho estatal, de un esfuerzo productor y reproductor del Estado. Su Mecánica social, su pretensión de "escribir una ciencia", la entendemos como un hecho intelectual inscrito en un proceso discursivo más general cuya institución genitora y, a la vez, beneficiaria, era el Estado. Su escrito inacabado era una de las tantas escrituras adheridas a la razón de Estado.

\section{Referencias bibliográficas}

Anónimo. (1835). Soliloquio de un abogado. Imprenta de Ayarza.

Azouvi, F. (1984). Psychologie et physiologie en France 1800-1830. History and Philosophy of the Life Science, 6(2), 151-170.

Baetschi, B. (2005). Diderot, Cabanis and Lamarck on Psycho-Physical Causality.

History and Philosophy of the Life Sciences, 27(3), 451-463.

Bajtin, M. (1982). Estética de la creación verbal. Siglo XXI. 
Barbara, J-G. (2012). Auguste Comte et la physiologie cérébrale de son temps. Revue d'histoire des sciences, 65(2), 213-236. https://doi.org/10.3917/rhs.652.0213

Blanckaert, C. (2000). 1800-Le moment "naturaliste" des sciences humaines. Revue d'Histoire des Sciences Humaines, 3, 117-160. https://doi.org/10.3917/ rhsh.003.0117

Bourdieu, P. (1993). Esprits d'État. Genèse et Structure du Champ bureaucratique. Actes de la Recherche en Sciences sociales, 96, 49-62.

Bourdieu, P. (1997). De la maison du roi a la raison d'Etat. Actes de la Recherche en Sciences Sociales, 118, 55-68.

Bourdieu, P. (2012). Sur l'État. Cours au Collège de France, 1989-1992. Éditions du Seuil.

Braunstein, J-F. (2012). L'invention française du «psychologisme » en 1828. Revue d'histoire des sciences, 65(2), 197.

Broussais, F-J-V. (1828). De l'irritation et de la folie. Ouvrage dans lequel les rapports du physique et du moral sont établis sur les bases de la médicine physiologique. Chez Mlle. Delaunay Librairie.

Cabanis, P. (1815). Rapports du physique et du moral de l'homme. Chez Caille et Ravier, Libraires.

Caldas, F. J. (1808). El influjo del clima sobre los seres organizados. Semanario del Nuevo Reyno de Granada, 22, 202-208.

Caro, J.E. (2002) [1836]. Mecánica social o teoría del movimiento humano, considerado en su naturaleza, en sus efectos y en sus causas. Instituto Caro y Cuervo.

Caro, J.E. (1954). Escritos filosóficos. Ministerio de Educación Nacional.

Chappey, J-L. (2000). L'Anthropologie et l'histoire naturelle de l'homme en 1800. Les enjeux d'un héritage. Annales historiques de la Révolution française, 320, 47-54. https://doi.org/10.4000/ahrf.142

Comte, A. (1829). Cours de Philosophie positive. 1ere et 2eme lecons. Libraires.

Comte, F-L-Ch. (1826). Traité de Législation, ou exposition des lois générales suivant lesquelles les peuples prospèrent, dépérissent ou restent stationnaires. Sautelet et Compagnie.

Dávila, J.M. (2007). La sensación es el principio del pensamiento. La introducción de la filosofía experimental en Colombia en el siglo XIX. Memoria y sociedad, 11(23), 73-92.

Destutt de Tracy, A. (1804). Éléments d'idéologie. Première partie. Idéologie proprement dite. Chez Courcier, Imprimeur.

Destutt de Tracy, A. (1818a). Éléments d'idéologie. Troisième partie. Logique. Mme Ve Courcier, Imprimeur-Libraire.

Destutt de Tracy, A. (1818b). Éléments d'idéologie. IVe et Ve Parties. Traité de la volonté et de ses effets. Mme Ve Courcier, Imprimeur-Libraire.

Duque Gómez, J. (1835). Colección de asertos del Colejio del Rosario. Universidad del Rosario.

Foucault, M. (2006). Seguridad, territorio y población. Curso en el College de France, 1977-1978. Fondo de Cultura Económica. 
Gélvez, C.R. (2011). José Eusebio Caro y la Mecánica social: el liberalismo de un conservador. (Universidad Nacional de Colombia, Maestría en Historia, 2011).

González, F. (1840). Elementos de ciencia administrativa. Imprenta de Cualla.

González, F. (1834). Certámenes públicos en el Colejio San Bartolomé. Imprenta de José Ayarza.

Jacoby, R. (1983). The Repression of Psychoanalysis: Otto Fenichel and the Political Freudians. Chicago University Press.

Jamin, J. (1979). Naissance de l'observation anthropologique : La Société des Observateurs de l'homme (1799-1805). Cahiers Internationaux de Sociologie, 67, 313-335.

Jaramillo Uribe, J. (1964). El pensamiento colombiano en el siglo XIX. Editorial Temis.

Jay, M. (2005). Songs of Experience: Modern American and European Variations on a Universal Theme. University of California Press.

Jay, M. (2011). Historical Explanation and the Event: Reflections on the Limits of Contextualization. New Literary History, 42(4), 557-571.

Koselleck, R. (1993). Futuro pasado: para una semántica de los tiempos históricos. Paidós.

Koselleck, R. \& Gadamer, H-G. (1997). Historia y hermenéutica. Paidós.

LaCapra, D. (1983). Rethinking Intellectual History: Texts, Contexts, Language. Cornell University Press.

LaCapra, D. (1975). A Preface to Sartre. A critical introduction to Sartre's Literary and Philosophical Writings. Cornell University Press.

Martínez Rodríguez, R. (2014). La primera controversia sobre el utilitarismo en Colombia (1825-1836): disputas entre las élites por el control de los fundamentos filosóficos del derecho. Revista Facultad de Derecho y Ciencias Políticas, 44(121), 721-766.

Mosquera, J. (1836). El benthamismo descubierto a la luz de la razón o documentos importantes para los padres de familia, estractados del Constitucional de Popayán. Imprenta de José Ayarza.

Ortega, F. (2015). República, tiempo incierto y moral en la primera mitad del siglo XIX. Almanack. Guarulhos, (10), 335-349. https://doi.org/10.1590/2236463320151007

Pocock, J.G.A. (1985). Virtue, Commerce, and History. Essays on Political Thought and History. Cambridge University Press.

Pocock, J.G.A. (1989). Politics, Language and Time: Essays on Political Thought and History. University of Chicago Press.

Pocock, J.G.A. (1975). The Machiavellian Moment. Florentin Political Thought and the Atlantic Republican Tradition. Princeton University Press.

Rojas, E. (1835). Certámenes públicos en el Colejio San Bartolomé. Imprenta de la Universidad.

Rosanvallon, P. (2003). Pour une histoire conceptuelle du politique. Éditions du Seuil.

Rosanvallon, P. (2011). La société des égaux. Éditions du Seuil. 
Saldarriaga Vélez, O. (2004). Gramática, epistemología y pedagogía en el siglo XIX: la polémica colombiana sobre los elementos de la ideología de Destutt de Tracy (1870). Memoria y Sociedad, 8(17), 41-59.

Skinner, Q. (1969). Meaning and Understanding in the History of Ideas. History and Theory, 1, 3-53. https://doi.org/10.2307/2504188

Skinner, Q. (1975). Hermeneutics and the Role of History. New Literary History, 1, 209-232. https://doi.org/10.2307/468286

Skinner, Q. (2002). Visions of Politics. Regarding Method. Cambridge University Press.

Torres, G. (1836). Observaciones sobre el decreto del gobierno acerca de la enseñanza de los principios de legislación por Jeremias Bentham. Imprenta de José Ayarza.

Varios (1835). Representación dirijida al Senado solicitando la proscripción del tratado de Lejislación de Jeremias Bentham, como también de los demás que contengan doctrinas perniciosas. Imprenta de José Ayarza. 